\title{
A Comparative Study of efficacy of Superoxidized solution against Povidone Iodine in the treatment of Diabetic Foot Ulcers
}

\author{
Dr. S.S. Meera ${ }^{1}$ M.S., Prof. N. Tamilselvan ${ }^{2}$ M.S., Dr. P. Satheeshkumar ${ }^{3}$ \\ ${ }^{1}$ (Assistant Professor of General Surgery, Government Mohan Kumaramangalam Medical College, Salem, \\ Tamilnadu, India.) \\ ${ }^{2}$ (Associate Professor of General Surgery, Government Mohan Kumaramangalam Medical College, Salem, \\ Tamilnadu, India.) \\ ${ }^{3}$ (Post Graduate, Department of General Surgery, Government Mohan Kumaramangalam Medical College, \\ Salem, Tamilnadu, India.)
}

\begin{abstract}
Diabetes is a common, non-communicable endocrine disorder which is a major culprit of morbidity and mortality of mankind at present. Of all known complications of Diabetes, Diabetic foot ranks first in decapitating the affecter's day today activities. According to WHO, 'Somewhere in the World, for every 30 seconds, a lower limb amputation is done due to Diabetes', in which the pathetic concern is that nearly $50 \%$ of all these diabetic leg amputations could have been prevented with basic medical care and awareness. Considering the burden of wound care on health system, this study is undertaken comparing the efficacy of Superoxide against Povidone Iodine in the treatment of Grade II and III Diabetic foot ulcers in our Medical College hospital. Out of 100 patients studied, superoxide was proved to be superior over Povidone Iodine in terms of time taken for the lesion to heal and disinfection of wound. Early detection, prompt debridement and wound care with Superoxide along with proper glycaemic control as a holistic approach definitely prevents morbid amputations.
\end{abstract}

Keywords: Diabetic foot, Superoxidized water, Povidone Iodine

\section{Introduction}

"It is unacceptable that so much disability and death are caused by leg amputations, when the solutions are clear and affordable"

Dr. Catherine Le Gales - Camus

Assistant Director-General, WHO.

Diabetes is a common, non-communicable endocrine disorder which is a major culprit of morbidity and mortality of mankind at present. WHO projects that Diabetes mellitus will be the $7^{\text {th }}$ leading cause of death in 2030. The global burden of the disease can be understood with WHO fact sheet that 347 million people worldwide suffer from Diabetes. Of all known complications of Diabetes, Diabetic foot ranks first in decapitating the affecter's day today activities. According to WHO, 'Somewhere in the World, for every 30 seconds, a lower limb amputation is done due to Diabetes', in which the pathetic concern is that nearly $50 \%$ of all these diabetic leg amputations could have been prevented with basic medical care and awareness. Considering the burden of wound care on health system, this study is undertaken comparing the efficacy of Superoxide against Povidone Iodine in the treatment of Grade II and III Diabetic foot ulcers in our Medical College hospital.

\section{Aims And Objectives}

- To compare the efficacy of Superoxide aqueous solution against Povidone Iodine on infected Diabetic foot ulcerations in terms of wound healing and disinfection.

- To compare the graded percentage decrease in ulcer size, peri-ulcer oedema and erythema, pus discharge and graded percentage increase in granulation tissue and epithelialisation.

III.1. Study type: Interventional

\section{Materials And Methods}

III.2. Study Design: Prospective Randomized Comparative study.

III.3. Study group: Over two years, 100 patients suffering from Grade 2 and 3 diaabetic ulcer foot ( according to University of TEXAS classification), who had either Type I or Type II Diabetes mellitus attending the General Surgery department of GMK medical college hospital, Salem were considered as data source. Individuals who fulfilled the inclusive and exclusive criteria were enrolled in the study and randomized to enter the study protocol. Out of 100 cases, 50 cases were randomized into Group A and 50 were randomized into 
Group B. In group A patients the ulcers were cleaned with Superoxidised solution and in Group B patients with Povidone Iodine after routine debridement.

\section{Iii.4. Inclusion Criteria}

1. Age : 20 to 70 years

2. Sex : both male and female

3. Both Type I and II Diabetic patients

4. Grade 2 and 3 Foot ulcers

\section{Iii.5. Exclusion Criteria}
1. Grade 1.4 and 5
2. Wound swab negative ulcers
3. Not willing to give consent
4. Vascular occlusion
5. Osteomyelitis in affected foot.

\section{Iii.6. Study Method Instituted:}

All patients were treated as Outpatients/ Inpatients by the foot care team comprising of General Surgeon, Diabetologist, Orthopaedician, Radiologist, Plastic Surgeon, Microbiologist and Staff nurse. Screening was done by Medical history, clinical examination and laboratory investigations. Clinical assessment was performed at the beginning of the treatment and at each dressing for each group. Detailed examinations were recorded every week. The necrotic tissues were removed by debridement with sterile precautions on each dressing. Area of each wound was calculated at weekly intervals by multiplying longest vertical and horizontal dimensions of Diabetic foot ulcers. Foot wear, offloading of ulcer and compliance were inspected at every visit and corrections were made when required. Cultures from the depth of the wounds were obtained at the beginning of the study and subsequently at end of every week and antibiotics were prescribed according to sensitivity. Bony involvement was excluded with the help of Radiographs and Orthopaedici surgeon's opinion. Vascular compromise was excluded by Doppler Arterial Study of affected limb. Glycaemic management was appropriately taken over by the physician. Both groups were treated until complete healing of the wound or until the wound becomes fit for skin grafting without any evidence of infection. Wound bed fitness for skin grafting was obtained from plastic surgeon. Statistical analysis of data from the Superoxidised solution treated Group (A) and Povidone Iodine treated Group (B) was done and results tabulated. Students T test (Paired samples ttest) was used as the statistical test to analyse the data obtained in this study.

Follow up: Regular Ulcer survey was made on days 1, 8, 15, 22, 29, 36, 43, 50, 57, 64, 71, 78, 85, 90 respectively.

\section{Results}

The present study of 100 patients prospectively randomized into A group (Superoxidised solution group) and B group ( Povidone Iodine group) of 50 patients each, was conducted with inclusion of same graded wounds in both groups. Every time, measurement of ulcer in square centimeters, measurement of granulation tissue in square centimeters, concomitant therapy and assessment of adverse effects were carried out and tabulated.

TABLE 1: Ulcer size assessment

\begin{tabular}{|l|l|l|}
\hline \multirow{2}{*}{ DAY } & \multicolumn{2}{|l|}{ PERCENTAGE DECREASE IN ULCER SIZE } \\
\cline { 2 - 3 } & SUPER OXIDE TREATED GROUP & POVIDONE IODINE TREATED GROUP \\
\hline 1 & BASELINE & BASELINE \\
\hline 8 & 19 & 15 \\
\hline 15 & 30 & 20 \\
\hline 22 & 70 & 50 \\
\hline 29 & 80 & 65 \\
\hline $\mathbf{P = 2 0 . 2 7 3 1 8 ~ S t u d e n t s ~ t ~ t e s t ~}$ & \multicolumn{2}{|l|}{} \\
\hline
\end{tabular}


TABLE 2: Statistical comparative depict of Ulcer size assessment

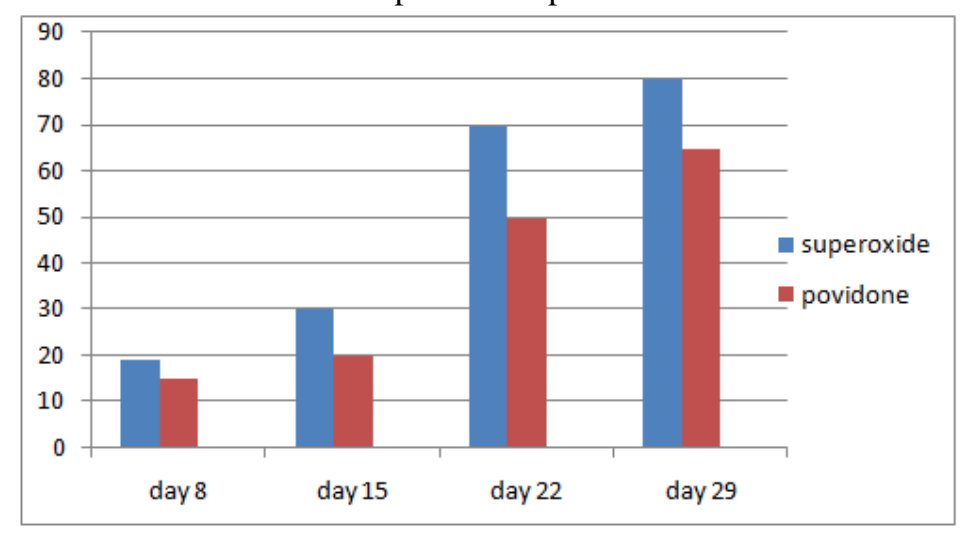

TABLE 3: Peri-Ulcer edema and erythema assessment

\begin{tabular}{|l|l|l|}
\hline \multirow{2}{*}{ DAY } & \multicolumn{2}{|l|}{ PERCENTAGE DECREASE IN PERI-ULCER EDEMA AND ERYTHEMA } \\
\cline { 2 - 3 } & SUPER OXIDE TREATED GROUP & POVIDONE TREATED GROUP \\
\hline 1 & BASELINE & BASELINE \\
\hline 8 & 55 & 45 \\
\hline 15 & 65 & 50 \\
\hline 22 & 70 & 55 \\
\hline 29 & 90 & 75 \\
\hline P+0,21297 students t test & \multicolumn{2}{|l}{} \\
\hline
\end{tabular}

TABLE 4: Statistical comparative depict of Decrease in peri-ulcer edema and erythema

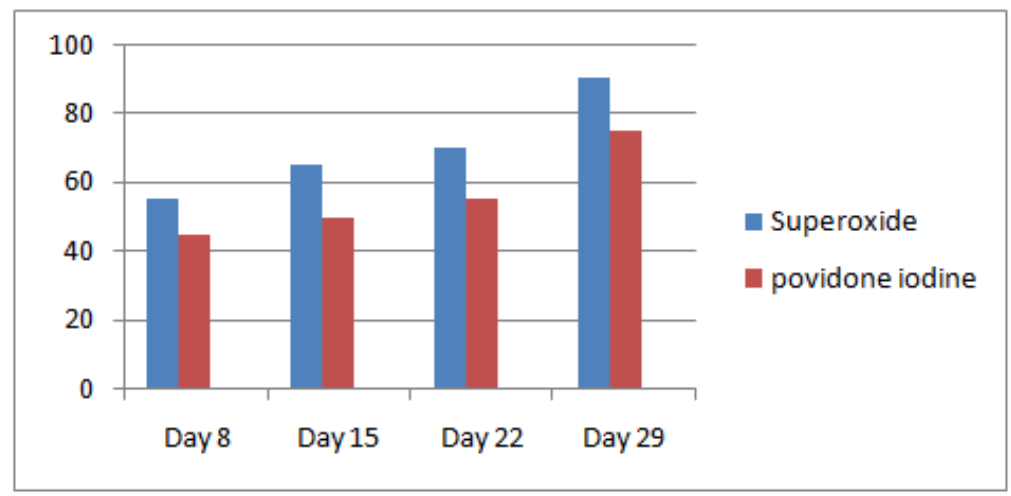

Superoxidised group developed healthy granulation tissue earlier than Povidone group. But, Povidone Iodine appeared granulo-toxic in healing ulcers thus delaying fitness for skin grafting.

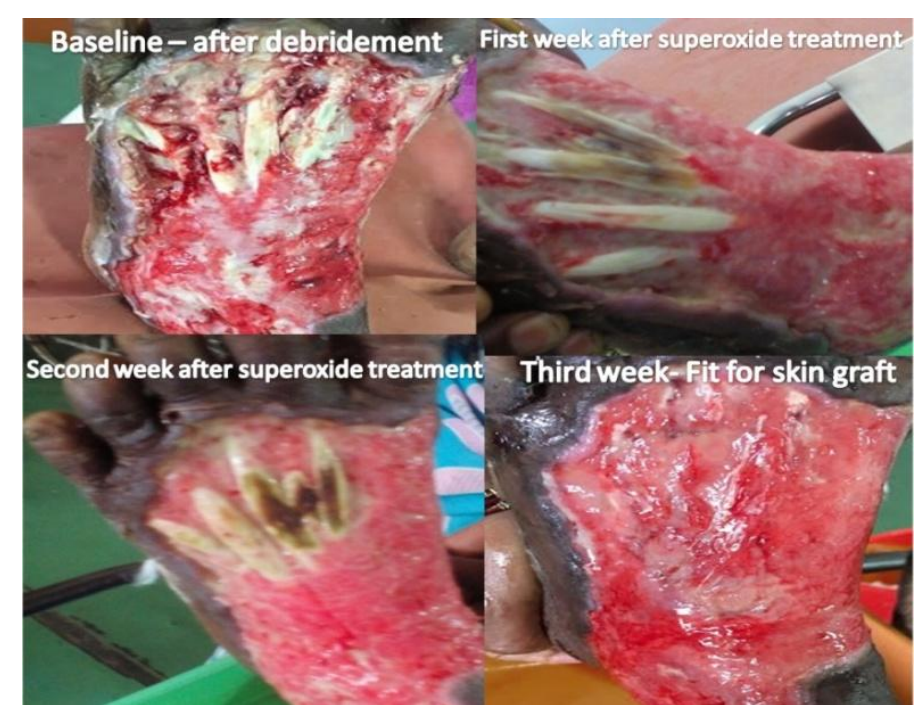

Fig 1: Superoxide Treated Group 
TABLE 5: Time to lesion healing

\begin{tabular}{|l|l|}
\hline MEAN HEALING TIME \\
\hline SUPER OXIDE TREATED GROUP & POVIDONE TREATED GROUP \\
\hline 40+_14 days & $55+\_14$ days \\
\hline
\end{tabular}

TABLE 6: Microbial culture and their outcome

\begin{tabular}{|l|l|}
\hline \multicolumn{2}{|l|}{ TIME TAKEN FOR NIL GROWTH IN CULTURE } \\
\hline SUPEROXIDE TREATED GROUP & POVIDONE TREATED GROUP \\
\hline $10+\_-5$ days & $25+-5$ days \\
\hline
\end{tabular}

Gram negative bacilli especially Klebsiella formed the major culprit of the isolated wound specimens as depicted in Fig 2.

\title{
MICROBE ISOLATED FROM ULCER
}

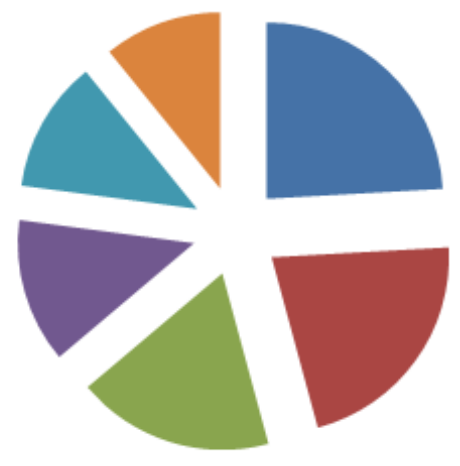

\author{
- Klebsiella $20 \%$ \\ - Staphylococcus $18 \%$ \\ Proteus $15 \%$ \\ Mixed flora $11 \%$ \\ E.coli $10 \%$ \\ CONS $9 \%$
}

Fig 2: Microbial burden of Diabetic foot Ulcer

In the present study, based on our results, it is concluded that the Superoxidised solution is superior than Povidone Iodine in terms of quick elimination of bacterial load of the ulcer, early wound healing, no tissue irritation and lower economical burden for the patient.

\section{Discussion}

In this current study, the comparison of Superoxidized solution with Povidone Iodine for treating the diabetic foot ulcer was done with the standard protocol and methods. The study has revealed a promising gateway in not only treating the diabetic foot ulcer and also in avoidance of amputations.

In this current study, patients treated with Superoxidised solution have shown early epithelialisation process and speedy granulation tissue formation, less time to lesion healing, earlier asepsis than the Povidone iodine treated group of patients. Also, there were no reported cases of allergy or irritation in Superoxidised solution treated group. As concluded by Pandey et al 2011, the efficacy of Superoxidised solution is superior over other antiseptic agents [4]. Many researchers have studied the effect of Povidone Iodine on not only diabetic foot ulcers but also many chronic wounds. But comparatively, the literature available on Superoxidised solution is minimal. Superoxide solution is relatively a new concept in wound dressing and started after 2003 only. The promising effects on antisepsis, faster wound healing and non-irritable nature of Superoxide solution's have prompted more people to use this solution for dressing diabetic foot ulcers than Povidone Iodine across the globe and a large scale of recognition is evident through the literatures [1,3].

In developing countries, Superoxide solution gains rapid importance due to its low cost and it is an economically feasible alternative over existing antiseptics. Superoxide solution is a $\mathrm{pH}$ neutral solution with a longer shelf life (>12 months) which acts by the difference in osmolarity of the solution and the pathogen's cell wall, resulting in lysis of the pathogen [5]. It has proved its antimicrobial activity against bacteria, viruses, fungi and bacterial spores. Superoxide solutions are electro-chemically processed aqueous solutions manufactured from pure water and USP grade sodium chloride. USP grade sodium chloride is a granular, white crystalline sodium chloride manufactured in United States of America under stringent process-control procedures, and is intended for pharmaceutical applications such as preparation of saline solutions for injection and dialysis [2]. The concept of electrolysis is very simple: tap water is purified through reverse osmosis (RO) and USP grade sodium chloride is added and then submitted to an electric field. During the process of electrolysis, molecules are pulled apart in a chamber with positive and negative poles and finally hypochlorite / hypochlorous species and free radicals are formed. The final result is a blend of high reactive species of chloride and oxygen as depicted in Fig. 3 


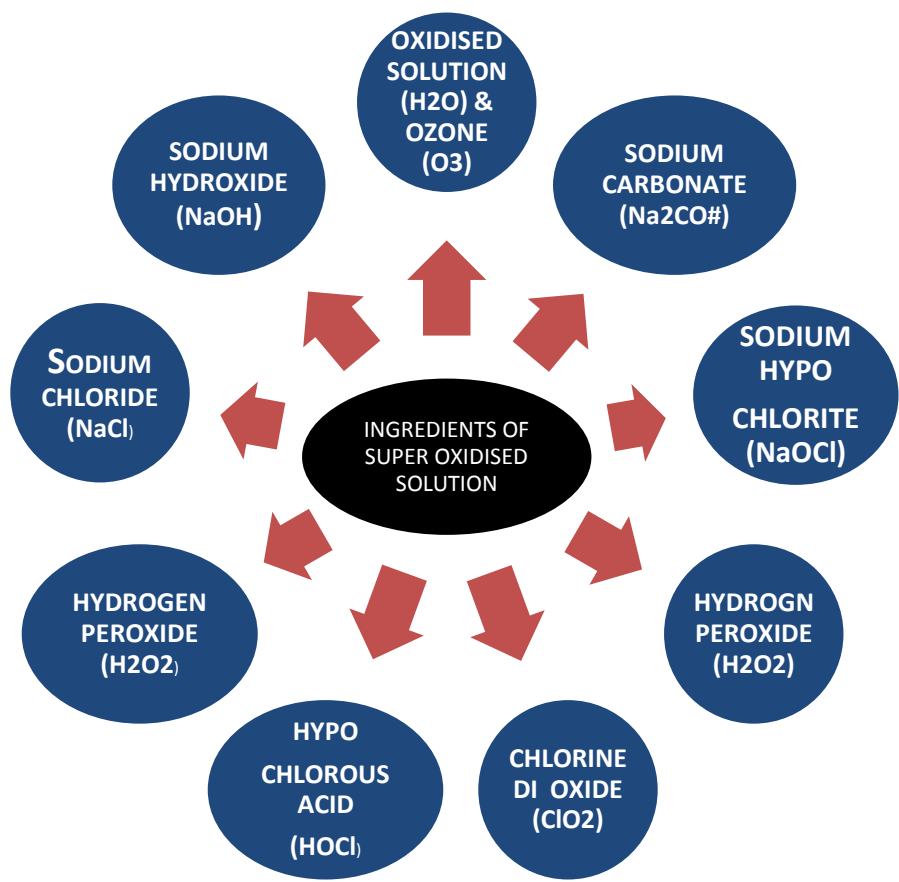

Fig 3: Ingredients of Superoxidized Solution

These ions and free radicals rapidly react and denature proteins of bacterial cell wall. They also have anti-inflammatory effect and produce an environment with an unbalanced osmolarity that damages single cell organism. The damage is due to direct result of the osmolarity difference between the concentrations of the ions in superoxidised solution versus the concentration of the same ions in the cell. Multicellular organisms are not prone to such osmolarity changes, therefore host tissues are spared only the single cell organisms are damaged and henceforth, it is host friendly [4].

\section{Conclusion}

Superoxidized solution is superior than the Povidone Iodine in the management of Diabetic Foot Ulcers (DFU) in terms of Quick elimination of bacterial load in DFU, Early wound healing, non irritation of patient tissue and lower economical burden to the community.

Dr. N. Tamilselvan M.S.,

\section{Acknowledgement(s)}

Selvi clinic, S.B. Towers,

Sundarapuram, Pollachi Main road,

Coimbatore 641024.

Mobile No: $\quad+91-9443066866$

Email Id: $\quad$ tselvancbe@gmail.com

\section{References}

[1]. Treating Infected Diabetic wounds with Superoxidised water as antiseptic agent: A preliminary experience - Syed Fazle Hadi, Tanwir Khaliq, Nighat Bilal, Imran Sikandar, Muhammad Saaiq et al JCPSP 2007, VOL. 17 (12): 740-743

[2]. Diabetic micro vascular complications today May/June 2006: Superoxidised water improves wound care outcomes in Diabetic patients - Cheryl M.Bongiovanni

[3]. Wounds 2006, Supplement to January 2006 - Clinical experience with a new and stable Superoxidised water in wound treatment , Tom A. Wolvos

[4]. P.K . Pandey et al ., International journal of Biological Medical Research 2011;2(4): 965-968 Outcomes of Superoxide solution dressings in surgical wounds: a randomised case control trial

[5]. Gutierrez AAC, Landa-Solis etal, Microcyn: a novel superoxidised water with neutral $\mathrm{pH}$ and disinfectant activity., Journal of Hospital Infection 2005xx1-9. 